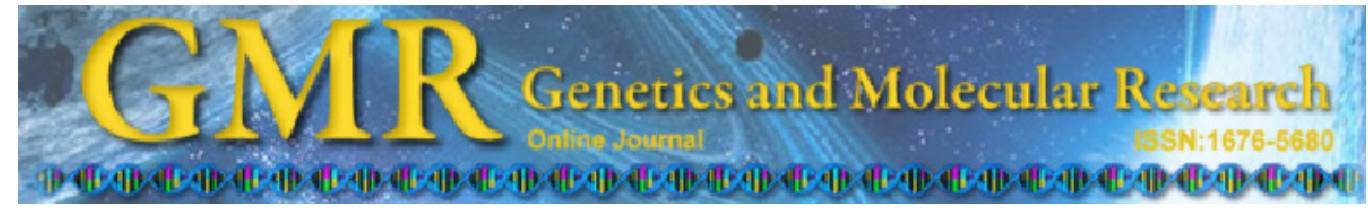

\title{
Serum lipid abnormalities are not associated with apoB 3' VNTR polymorphism in nephrotic children
}

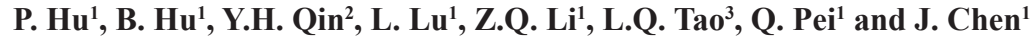 \\ 'Department of Pediatrics, First Affiliated Hospital, \\ Anhui Medical University, Hefei, China \\ ${ }^{2}$ Department of Pediatrics, First Affiliated Hospital, \\ Guangxi Medical University, Nanning, China \\ ${ }^{3}$ Anhui Provincial Children's Hospital, Anhui Medical University, \\ Hefei, China \\ Corresponding author: P. Hu \\ E-mail: hupeng28@hotmail.com
}

Genet. Mol. Res. 12 (1): 765-774 (2013)

Received June 15, 2012

Accepted November 23, 2012

Published March 13, 2013

DOI http://dx.doi.org/10.4238/2013.March.13.5

\begin{abstract}
Apolipoprotein B (apoB) gene 3' variable number of tandem repeat (VNTR) is highly variable, and therefore can be an informative marker for associative analysis of lipid metabolism. This is the first report focusing on a possible association of apoB VNTR polymorphism with nephrotic hyperlipidemia. Genomic DNA was extracted from 500 children with primary nephrotic syndrome (PNS) and 500 healthy controls. The apoB genotype was determined by PCR analysis. Allele size distribution followed a unimodal curve, with the main peak at the hypervariable element 35 (HVE35); the most prevalent genotype was HVE35/35 in both control and PNS children. The genotype and allele distributions of apoB variants in PNS children were not significantly different from controls. There was significant variation in serum lipid profiles among different genotypes in control children. Individuals with the long (L) allele exhibited significantly higher total cholesterol, low-density lipoprotein cholesterol (LDL-C)
\end{abstract}


and apoB levels than those with the medium (M) or short (S) allele; consequently, $\mathrm{M} / \mathrm{L}$ carriers had significantly higher total cholesterol, LDL-C and apoB concentrations than $\operatorname{did} \mathrm{S} / \mathrm{S}, \mathrm{S} / \mathrm{M}, \mathrm{S} / \mathrm{L}$, or $\mathrm{M} / \mathrm{M}$ carriers. However, in PNS children, no significant differences in serum lipid levels were observed among individuals with different genotypes and alleles of apoB 3' VNTR. We conclude that hyperlipidemia in nephrotic children is not associated with apoB 3' VNTR polymorphism.

Key words: Apolipoprotein B; Genetic variation; Hyperlipidemia; Child; Nephrotic syndrome

\section{INTRODUCTION}

Primary nephrotic syndrome (PNS) is the most prevalent renal disease in childhood and is characterized by elevated permeability of the glomerular filtration barrier and subsequent inability to restrict the urinary loss of protein (Gordillo and Spitzer, 2009). Hyperlipidemia (HLP) not only acts as a typical clinical manifestation of PNS but also is involved in cardiovascular disease and progressive glomerular damage (Mitsnefes, 2008; Hu et al., 2012). In addition, both of the above hazards may prove to be long-term factors that persist from childhood into adulthood (Lechner et al., 2004). Generally, increased concentrations of cholesterol, triglycerides (TGs), lipoprotein (a) [Lp(a)], low-density lipoprotein (LDL), veryLDL, and apolipoprotein B (apoB) are the common features of serum lipid abnormalities in nephrotic children (Hu et al., 2009a). Several mechanisms allegedly contribute to nephrotic HLP. According to the classic view, hypercholesterolemia is due to increased hepatic synthesis of apoB-containing lipoproteins, whereas hypertriglyceridemia results from impaired catabolism of TG-rich lipoproteins (Dixit and Hettiaratchi, 1979; Cohen et al., 1980). Furthermore, some studies have documented that genetics may play an important role in the onset of nephrotic HLP (Gong et al., 2000; Ruf et al., 2003; Hu et al., 2009b).

ApoB is the integral structure protein of hepatic very-low-density lipoprotein and serves as a principal ligand for LDL-receptor-mediated lipoprotein clearance (Segrest et al., 2001). The variability of the apoB gene may account in part for the genetic susceptibility to HLP by modulating the average effects of apoB variants of the lipidemic phenotype (Rantala et al., 2000; Hu et al., 2009c). The apoB gene maps to human chromosome 2p24 and comprises 29 exons spanning approximately $42 \mathrm{~kb}$. Numerous polymorphisms have been identified on this gene. Among them, the apoB gene 3' variable number of tandem repeat (VNTR) polymorphism is located $482 \mathrm{bp}$ downstream of the stop codon and exhibits a variable number of 11- to 16-bp (average variation, 15-bp) adenine- $(\mathrm{A})$ and thymine- $(\mathrm{T})$ rich sequences (Huang and Breslow, 1987). This locus is highly variable, and approximately 26 alleles have been reported (Destro-Bisol et al., 1994). Therefore, the apoB 3' VNTR is considered an informative marker for many applications, including linkage analysis, forensic identification, paternity testing, anthropological research, and phylogenetic studies (Batanian et al., 1998; Choong et al., 1999; Soares-Vieira et al., 2000; Verbenko et al., 2003; Khrunin et al., 2007).

In a previous study, we identified the higher repeat alleles of the apoB $3^{\prime}$ VNTR as a potential risk factor for HLP in Han children from central China (Hu et al., 2010). However, what remains to be resolved is whether the apoB 3' VNTR polymorphism effect on lipid metabolism also exists in nephrotic children. 


\section{MATERIAL AND METHODS}

\section{Subjects}

To avoid unnecessary interruptions in the treatment of the disease and steroid-to-lipid metabolism and proteinuria, 500 pediatric patients with PNS aged between 2 and 14 years (mean age, $8.4 \pm 3.6$ years) were recruited to the study at their first visit, and none was undergoing steroid therapy or other medications. All patients had nephrotic onset with proteinuria $>50 \mathrm{mg} \cdot \mathrm{kg}^{-1} \cdot \mathrm{day}^{-1}$, hypoalbuminemia $<30 \mathrm{~g} / \mathrm{L}$, edema, and HLP of varying degrees (Gipson et al., 2009). The control group consisted of 500 healthy volunteers aged between 3 and 14 years (mean age, $7.8 \pm 3.2$ years) without allergies or renal disease. The ethnicities of both groups were Han Chinese, and recruited individuals were unrelated and not members of the same family or related. The study was approved by the Ethics Committee of the Medical Facility, and written informed consent was obtained from the parents of all subjects before study entry.

\section{Laboratory analysis}

Blood samples for the measurement of serum lipid parameters were collected after an overnight fast during the first visit to the hospital. Serum was separated within $4 \mathrm{~h}$ and stored. Subsequent analysis of serum Lp(a) was performed using an assay based on a sandwich enzyme-linked immunosorbent assay that was insensitive to the presence of plasminogen (RANDOX, UK). The sensitivity and specificity of the enzyme-linked immunosorbent assay were 98.2 and $95.7 \%$, respectively, and this test was not validated against manufacturer claims. Serum total cholesterol (TC), TG, and high-density lipoprotein cholesterol (HDL-C) were measured using standard enzymatic methods (RANDOX). Serum LDL-C was calculated with the Friedewald formula (Bairaktari et al., 2000). Serum apolipoprotein A1 (apoA1) and apoB were measured using immunoturbidimetric methods (RANDOX). All analyses were performed in duplicate, and the examiners were blinded to the clinical and laboratory results.

\section{Genotyping of the apoB gene 3' VNTR locus}

DNA was extracted from blood with a salting out method using phenol-chloroform as described by Noguera et al. (2000). The amplification of the apoB gene 3' VNTR locus was undertaken with polymerase chain reaction. The sequences of the forward and backward primers used were 5'-ATG GAA ACG GAG AAA TTA TG-3' and 5'-CCT TCT CAC TTG GCA AAT AC-3' (Boerwinkle et al., 1989). The reaction mixture $(50 \mu \mathrm{L})$ was prepared with 10 pmol of each primer, $100 \mathrm{mM}$ deoxyribonucleotide triphosphates, $1 \mathrm{U}$ Taq polymerase (TaKaRa, Dalian, China), buffer containing $1.5 \mathrm{mM} \mathrm{MgCl}_{2}, 1 \%$ dimethyl sulfoxide, and $500 \mathrm{ng}$ DNA sample. The amplification process consisted of an initial denaturation at $95^{\circ} \mathrm{C}$ for $5 \mathrm{~min}$, followed by 30 cycles of denaturation at $95^{\circ} \mathrm{C}$ for $1 \mathrm{~min}$, coiling at $58^{\circ} \mathrm{C}$ for $1 \mathrm{~min}$, extension at $72^{\circ} \mathrm{C}$ for $1 \mathrm{~min}$, and a final extension at $72^{\circ} \mathrm{C}$ for $10 \mathrm{~min}$. Negative controls (no DNA added) were included in every polymerase chain reaction run to check for contamination. To separate the 3' VNTR alleles, $10 \mu \mathrm{L}$ amplified DNA was run on a 3\% agarose gel with ethidium bromide. The gel was visualized under ultraviolet light and photographed (Figure 1). The length of each band was determined using an ABI 3100 Automated DNA 114 Sequencer (Applera, 
San Francisco, CA, USA). The number of tandem repeats was calculated with the following equation: repeat number $=[$ fragment length $(b p)-138$ bp] $/ 15$ bp (Ruixing et al., 2007).

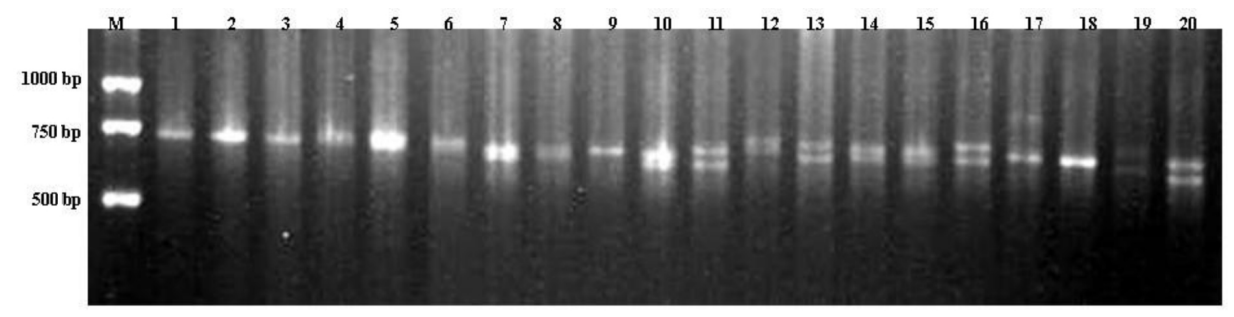

Figure 1. Representative gel photogragh of PCR product amplified for apoB 3 ' VNTR. Lane $M=$ DNA ladder markers; lane $1=$ hypervariable element $(\mathrm{HVE}) 40 / 40$; lane $2=\mathrm{HVE} 38 / 38$; lane $3=\mathrm{HVE} 37 / 37$; lane $4=\mathrm{HVE} 36 / 36$; lane $5=$ HVE35/35; lane $6=\mathrm{HVE} 34 / 34$; lane $7=\mathrm{HVE} 30 / 32$; lane $8=\mathrm{HVE30} / 32$; lane $9=\mathrm{HVE} 32 / 32$; lane $10=\mathrm{HVE} 28 / 30$; lane $11=\mathrm{HVE} 26 / 32$; lane $12=\mathrm{HVE} 32 / 36$; lane $13=\mathrm{HVE} 28 / 32$; lane $14=\mathrm{HVE} 28 / 30$; lane $15=\mathrm{HVE} 26 / 30$; lane $16=\mathrm{HVE} 26 / 32$; lane $17=\mathrm{HVE} 30 / 44$; lane $18=\mathrm{HVE} 28 / 28$; lane $19=\mathrm{HVE} 24 / 30 ;$ lane $20=\mathrm{HVE} 22 / 24$.

\section{Statistical analyses}

A P value of $<0.05$ was considered to be significant. The results are reported as means \pm standard deviations or percentages. The allelic frequencies and genotype distribution were calculated with a gene-counting method (Yasuda and Kimura, 1968). The chi-square test or the Fisher exact test was used to evaluate the allelic and genotypic frequencies and estimate Hardy-Weinberg equilibrium. One-way analysis of variance and the Student $t$-test were performed to determine differences in lipid parameters. Statistical analyses were performed using SPSS version 11.5.

\section{RESULTS}

\section{Demographic and laboratory characteristics}

The clinical and biochemical characteristics of children in PNS and control groups are shown in Table 1. Gender ratio and age were very close in the two groups $(\mathrm{P}>0.05)$. However, serum concentrations of $\mathrm{Lp}(\mathrm{a}), \mathrm{TC}, \mathrm{TG}, \mathrm{HDL}-\mathrm{C}, \mathrm{LDL}-\mathrm{C}$, and apoB in the PNS group were significantly higher than those in the control group $(\mathrm{P}<0.01)$.

Table 1. Clinical and biochemical characteristics of controls and primary nephrotic syndrome (PNS) children.

\begin{tabular}{lccr}
\hline & Controls $(\mathrm{N}=500)$ & PNS children $(\mathrm{N}=500)$ & $\mathrm{P}$ \\
\hline Gender ratio (M/F) & $276 / 224$ & $282 / 218$ & 0.702 \\
Age (years) & $7.5 \pm 3.6$ & $8.3 \pm 3.7$ & 0.732 \\
Lp(a) (mg/L) & $354.9 \pm 28.6$ & $839.6 \pm 35.2$ & 0.001 \\
TC (mM) & $3.7 \pm 0.8$ & $9.1 \pm 1.3$ & 0.001 \\
TG (mM) & $1.1 \pm 0.4$ & $2.6 \pm 0.4$ & 0.001 \\
HDL-C (mM) & $1.0 \pm 0.4$ & $1.9 \pm 0.3$ & 0.003 \\
LDL-C (mM) & $3.2 \pm 0.7$ & $7.3 \pm 1.2$ & 0.001 \\
ApoA1 (mM) & $1.7 \pm 0.2$ & $1.8 \pm 0.3$ & 0.947 \\
ApoB (mM) & $0.8 \pm 0.3$ & $1.6 \pm 0.5$ & 0.001 \\
\hline
\end{tabular}

Data are reported as means \pm SD. For abbreviations, see legend to Table 4. 


\section{Allelic frequencies and genotype distribution}

Fourteen alleles of apoB 3' VNTR comprising 22 to 44 hypervariable elements (HVEs) were identified in our populations. They were HVE22, HVE24, HVE26, HVE28, HVE30, HVE32, HVE34, HVE35, HVE36, HVE37, HVE38, HVE40, HVE42, and HVE44. With the exception of HVE44, all of these alleles were present in controls, whereas HVE22 and HVE42 were absent in children with PNS (Figure 2). The genotype distribution in the populations did not follow the Hardy-Weinberg equilibrium but rather displayed a unimodal curve in both groups with the main peak at HVE35, a second peak at HVE34, and a third peak at HVE36 (58.0 vs 55.4, 16.8 vs 18.7, and 11.5 vs 10.8\%, respectively). Thirty-seven genotypes were detected in the control and PNS groups, with the most frequent being HVE35/35; the second most frequent was HVE34/35, and the third was 35/36 (36.4 vs 33.4, 20.6 vs 21.2, and $18.4 v s$ 16.6\%, respectively; Table 2).

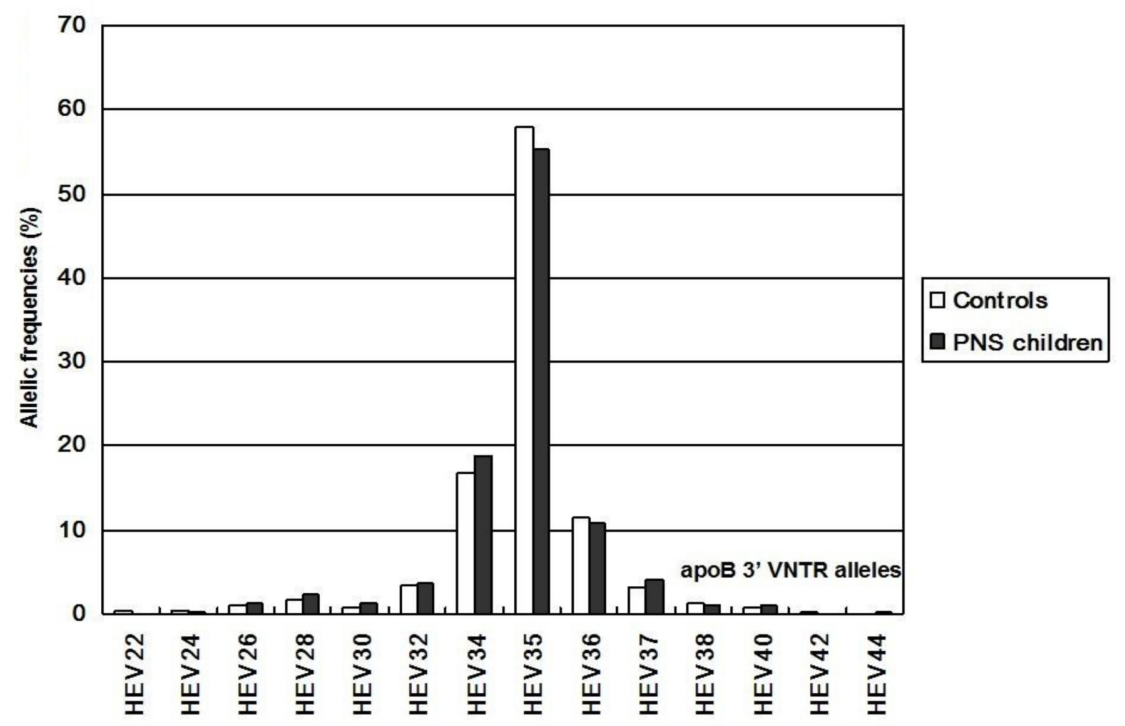

Figure 2. Allelic frequencies of apoB $3^{\prime}$ VNTR in control and primary nephrotic syndrome (PNS) children. Allelic distribution followed a unimodal curve in controls and PNS with the main peak at hypervariable element (HVE) 35 , the second at HVE34 and the third at HVE36 (58.0 vs 55.4, 16.8 vs 18.7, and $11.5 v s$ 10.8\%, respectively).

To make the analysis uncomplicated, we coded alleles in a three-allele model. Up to 32 repeats were kept in the short (S) allele group, the most common alleles (34-38 repeats) were in the medium (M) group, and the long (L) allele group included more than 40 repeats. Three homozygous phenotypes ( $\mathrm{S} / \mathrm{S}, \mathrm{M} / \mathrm{M}$, and $\mathrm{L} / \mathrm{L}$ ) and three heterozygous phenotypes $(\mathrm{S} / \mathrm{M}$, $\mathrm{S} / \mathrm{L}$, and M/L) arise from the expression of any two of the three alleles (Dixit et al., 2008). The genotype and allelic frequencies of the apoB 3' VNTR locus in the control and PNS groups are shown in Table 3 . The genotype distribution in children with PNS was not significantly different from that in controls (chi-square $=2.170, \mathrm{P}=0.830$ ). Similarly, no significant differences in allelic frequencies were observed for the apoB 3' VNTR in children with PNS compared with those in controls (chi-square $=0.220, \mathrm{P}=0.900$ ). 
Table 2. Genotype distribution of apoB 3' VNTR in control and primary nephrotic syndrome (PNS) children.

\begin{tabular}{|c|c|c|c|c|c|}
\hline \multicolumn{3}{|c|}{ Controls $(\mathrm{N}=500)$} & \multicolumn{3}{|c|}{ PNS children $(\mathrm{N}=500)$} \\
\hline Genotype & Cases & Percentage (\%) & Genotype & Cases & Percentage $(\%)$ \\
\hline HVE35/35 & 182 & 36.4 & HVE35/35 & 167 & 33.4 \\
\hline HVE34/35 & 103 & 20.6 & HVE34/35 & 107 & 21.2 \\
\hline HVE35/36 & 92 & 18.4 & HVE35/36 & 83 & 16.6 \\
\hline HVE35/37 & 21 & 4.2 & HVE35/37 & 25 & 5.0 \\
\hline HVE34/34 & 15 & 3.0 & HVE34/34 & 20 & 4.0 \\
\hline HVE32/34 & 8 & 1.6 & HVE34/36 & 9 & 1.8 \\
\hline HVE34/36 & 8 & 1.6 & HVE32/34 & 7 & 1.4 \\
\hline HVE34/37 & 6 & 1.2 & HVE34/37 & 7 & 1.4 \\
\hline HVE28/34 & 5 & 1.0 & HVE28/34 & 6 & 1.2 \\
\hline HVE30/32 & 5 & 1.0 & HVE30/32 & 6 & 1.2 \\
\hline HVE34/38 & 5 & 1.0 & HVE34/38 & 6 & 1.2 \\
\hline HVE32/36 & 4 & 0.8 & HVE32/35 & 5 & 1.0 \\
\hline HVE36/36 & 4 & 0.8 & HVE36/36 & 5 & 1.0 \\
\hline HVE28/32 & 3 & 0.6 & HVE28/32 & 4 & 0.8 \\
\hline HVE32/32 & 3 & 0.6 & HVE32/32 & 4 & 0.8 \\
\hline HVE32/34 & 3 & 0.6 & HVE32/34 & 4 & 0.8 \\
\hline HVE36/40 & 3 & 0.6 & HVE36/40 & 4 & 0.8 \\
\hline HVE37/37 & 3 & 0.6 & HVE37/37 & 4 & 0.8 \\
\hline HVE $22 / 24$ & 2 & 0.4 & HVE26/26 & 3 & 0.6 \\
\hline HVE22/26 & 2 & 0.4 & HVE26/28 & 3 & 0.6 \\
\hline HVE26/26 & 2 & 0.4 & HVE26/30 & 3 & 0.6 \\
\hline HVE26/28 & 2 & 0.4 & HVE28/28 & 3 & 0.6 \\
\hline HVE26/32 & 2 & 0.4 & HVE28/30 & 3 & 0.6 \\
\hline HVE28/28 & 2 & 0.4 & HVE24/36 & 2 & 0.4 \\
\hline HVE28/30 & 2 & 0.4 & HVE32/38 & 2 & 0.4 \\
\hline HVE32/38 & 2 & 0.4 & HVE28/40 & 2 & 0.4 \\
\hline HVE22/38 & 1 & 0.2 & HVE37/44 & 2 & 0.4 \\
\hline HVE24/30 & 1 & 0.2 & HVE34/40 & 1 & 0.2 \\
\hline HVE24/38 & 1 & 0.2 & HVE38/38 & 1 & 0.2 \\
\hline HVE28/40 & 1 & 0.2 & HVE38/40 & 1 & 0.2 \\
\hline HVE30/44 & 1 & 0.2 & HVE40/40 & 1 & 0.2 \\
\hline HVE32/40 & 1 & 0.2 & & & \\
\hline HVE32/42 & 1 & 0.2 & & & \\
\hline HVE38/38 & 1 & 0.2 & & & \\
\hline HVE38/40 & 1 & 0.2 & & & \\
\hline HVE38/42 & 1 & 0.2 & & & \\
\hline HVE40/40 & 1 & 0.2 & & & \\
\hline
\end{tabular}

Table 3. Genotype and allelic frequencies of apoB 3' VNTR in control and primary nephrotic syndrome (PNS) children.

\begin{tabular}{lccc}
\hline Genotype or allele & Controls $[\mathrm{N}=500(\%)]$ & PNS children $[\mathrm{N}=500(\%)]$ & $\chi^{2}$ \\
\hline $\mathrm{S} / \mathrm{S}$ & $26(5.2)$ & $29(5.8)$ & \\
$\mathrm{S} / \mathrm{M}$ & $21(4.2)$ & $26(5.2)$ & \\
$\mathrm{S} / \mathrm{L}$ & $4(0.8)$ & $2(0.4)$ & \\
$\mathrm{M} / \mathrm{M}$ & $443(88.6)$ & $434(86.8)$ & 2.170 \\
$\mathrm{M} / \mathrm{L}$ & $5(1.0)$ & $8(1.6)$ & 0.830 \\
$\mathrm{~L} / \mathrm{L}$ & $1(0.2)$ & $1(0.2)$ & \\
$\mathrm{S}$ & $38.5(7.7)$ & $43(8.6)$ & 0.220 \\
$\mathrm{M}$ & $456(91.2)$ & $451(90.2)$ & 0.900 \\
$\mathrm{~L}$ & $5.5(1.1)$ & $6(1.2)$ &
\end{tabular}

\section{Influence of apoB 3' VNTR polymorphism on lipid profiles}

Serum lipid concentrations according to the genetic polymorphisms of apoB 3' VNTR 
are presented in Table 4. Because only one nephrotic and one healthy child displayed $\mathrm{L} / \mathrm{L}$ and two nephrotic children displayed S/L, the contributions of these genotypes to serum lipid components could not be evaluated. To probe the association of serum lipids with the alleles of the apoB 3' VNTR, we divided subjects into three carrier subgroups: S (S/S and S/M), M (M/M), and $\mathrm{L}(\mathrm{M} / \mathrm{L}$ and $\mathrm{L} / \mathrm{L})$. Individuals with $\mathrm{S} / \mathrm{L}$ were excluded from the analysis because of the uncertainty about pooling with other genotypes. In controls, significant variation among the five genotypes was seen for serum levels of TC, LDL-C, and apoB. M/L carriers had TC, LDL-C, and apoB concentrations significantly higher than those of $\mathrm{S} / \mathrm{S}, \mathrm{S} / \mathrm{M}, \mathrm{S} / \mathrm{L}$, or $\mathrm{M} / \mathrm{M}$ carriers $(\mathrm{P}<$ $0.05)$. In addition, the same trend was also observed among the three alleles. Individuals with the L allele exhibited significantly higher TC, LDL-C, and apoB levels than those with the M or $\mathrm{S}$ alleles $(\mathrm{P}<0.05)$. However, in the PNS group, no significant differences in serum lipid levels were observed for variant genotypes and alleles of the apoB 3' VNTR $(\mathrm{P}>0.05)$.

Table 4. Influence of apoB 3' variable number of tandem repeat polymorphism on lipid profiles in control and primary nephrotic syndrome (PNS) children.

\begin{tabular}{|c|c|c|c|c|c|c|c|c|}
\hline & $\mathrm{S} / \mathrm{S}$ & $\mathrm{S} / \mathrm{M}$ & $\mathrm{S} / \mathrm{L}$ & $\mathrm{M} / \mathrm{M}$ & $\mathrm{M} / \mathrm{L}$ & $\mathrm{S}$ & M & $\mathrm{L}$ \\
\hline \multicolumn{9}{|l|}{ Controls } \\
\hline $\mathrm{N}=500$ & 26 & 21 & 4 & 443 & 5 & 47 & 443 & 6 \\
\hline $\mathrm{Lp}(\mathrm{a})(\mathrm{mg} / \mathrm{L})$ & $348.3 \pm 32.7$ & $359.6 \pm 38.5$ & $351.5 \pm 62.3$ & $362.5 \pm 21.3$ & $365.1 \pm 55.3$ & $353.1 \pm 34.2$ & $362.5 \pm 21.3$ & $366.3 \pm 50.6$ \\
\hline $\mathrm{TC}(\mathrm{mM})$ & $3.6 \pm 1.2$ & $3.8 \pm 0.9$ & $3.7 \pm 1.4$ & $3.8 \pm 0.7$ & $4.3 \pm 1.4^{*}$ & $3.6 \pm 0.8$ & $3.8 \pm 0.7$ & $4.4 \pm 1.2^{*}$ \\
\hline $\mathrm{TG}(\mathrm{mM})$ & $0.8 \pm 0.3$ & $0.9 \pm 0.3$ & $1.0 \pm 0.5$ & $1.0 \pm 0.5$ & $1.1 \pm 0.6$ & $0.8 \pm 0.3$ & $1.0 \pm 0.5$ & $1.1 \pm 0.4$ \\
\hline HDL-C (mM) & $1.5 \pm 0.4$ & $1.6 \pm 0.6$ & $1.5 \pm 0.6$ & $1.3 \pm 0.1$ & $1.5 \pm 0.8$ & $1.5 \pm 0.5$ & $1.3 \pm 0.1$ & $1.5 \pm 0.6$ \\
\hline LDL-C (mM) & $2.5 \pm 0.7$ & $3.2 \pm 0.8$ & $2.7 \pm 0.9$ & $3.1 \pm 0.5$ & $3.6 \pm 1.1^{*}$ & $2.7 \pm 0.7$ & $3.1 \pm 0.5$ & $3.5 \pm 0.9^{*}$ \\
\hline $\operatorname{apoA} 1(g / L)$ & $1.5 \pm 0.5$ & $1.5 \pm 0.4$ & $1.4 \pm 0.6$ & $1.6 \pm 0.2$ & $1.4 \pm 0.4$ & $1.5 \pm 0.4$ & $1.6 \pm 0.2$ & $1.3 \pm 0.5$ \\
\hline apoB $(\mathrm{g} / \mathrm{L})$ & $0.7 \pm 0.2$ & $0.9 \pm 0.4$ & $0.8 \pm 0.4$ & $0.9 \pm 0.2$ & $1.3 \pm 0.3^{*}$ & $0.8 \pm 0.4$ & $0.9 \pm 0.2$ & $1.3 \pm 0.3^{*}$ \\
\hline \multicolumn{9}{|l|}{ PNS children } \\
\hline $\mathrm{N}=500$ & 29 & 26 & 2 & 434 & 8 & 55 & 434 & 9 \\
\hline $\mathrm{Lp}(\mathrm{a})(\mathrm{mg} / \mathrm{L})$ & $835.3 \pm 44.2$ & $841.0 \pm 42.5$ & - & $831.1 \pm 40.3$ & $846.4 \pm 67.9$ & $837.6 \pm 36.5$ & $831.1 \pm 40.3$ & $843.9 \pm 65.4$ \\
\hline $\mathrm{TC}(\mathrm{mM})$ & $8.9 \pm 1.5$ & $9.1 \pm 1.6$ & - & $9.3 \pm 1.5$ & $9.5 \pm 1$ & $8.9 \pm 1.3$ & $9.3 \pm 1.5$ & $9.4 \pm 1.6$ \\
\hline $\mathrm{TG}(\mathrm{mM})$ & $2.5 \pm 1.0$ & $2.7 \pm 1.3$ & - & $2.8 \pm 0.6$ & $2.8 \pm 1.3$ & $2.5 \pm 0.8$ & $2.8 \pm 0.6$ & $2.8 \pm 1.4$ \\
\hline HDL-C (mM) & $1.9 \pm 0.5$ & $2.1 \pm 0.5$ & - & $2.0 \pm 0.3$ & $1.8 \pm 0.6$ & $2.0 \pm 0.6$ & $2.0 \pm 0.3$ & $1.9 \pm 0.6$ \\
\hline LDL-C (mM) & $6.9 \pm 1.1$ & $7.3 \pm 1.4$ & - & $6.9 \pm 1.5$ & $7.5 \pm 2.2$ & $7.0 \pm 1.2$ & $6.9 \pm 1.5$ & $7.4 \pm 1.9$ \\
\hline $\operatorname{apoA1}(\mathrm{g} / \mathrm{L})$ & $1.8 \pm 0.6$ & $1.8 \pm 0.4$ & - & $2.0 \pm 0.4$ & $2.1 \pm 0.6$ & $1.8 \pm 0.6$ & $2.0 \pm 0.4$ & $2.0 \pm 0.4$ \\
\hline apoB $(\mathrm{g} / \mathrm{L})$ & $1.6 \pm 0.3$ & $1.8 \pm 0.6$ & - & $1.7 \pm 0.4$ & $1.9 \pm 0.7$ & $1.6 \pm 0.5$ & $1.7 \pm 0.4$ & $1.9 \pm 0.7$ \\
\hline
\end{tabular}

Data are reported as means $\pm \mathrm{SD}$. $* \mathrm{P}<0.05$. In control children, $\mathrm{M} / \mathrm{L}$ carriers had significantly higher total cholesterol (TC), low-density lipoprotein cholesterol (LDL-C) and apolipoprotein B (apoB) concentrations than did $\mathrm{S} / \mathrm{S}, \mathrm{S} / \mathrm{M}, \mathrm{S} / \mathrm{L}$, or $\mathrm{M} / \mathrm{M}$ carriers $(\mathrm{P}<0.05)$; accordingly, individuals with the $\mathrm{L}$ allele exhibited significantly higher TC, LDL-C, and apoB than those with $\mathrm{M}$ or $\mathrm{S}$ allele $(\mathrm{P}<0.05)$. Lp $(\mathrm{a})=$ lipoprotein (a); TG $=$ triglycerides; HDL-C = high-density lipoprotein cholesterol; apoA1 = apolipoprotein $\mathrm{A} 1 . \mathrm{S}=$ short; $\mathrm{M}=$ medium; $\mathrm{L}=$ long alleles.

\section{DISCUSSION}

HLP is one of the most common pathophysiological features in nephrotic children (Gordillo and Spitzer, 2009). In the present study, patients with childhood PNS experienced profound dyslipidemia characterized by significant increases in Lp(a), TC, TG, HDL-C, LDL$\mathrm{C}$, and apoB levels. Although many factors appear to be implicated in the pathogenesis of PNS-related lipid abnormalities, the underlying mechanisms remain a matter of debate. Increasing evidence suggests that these disturbances and mass proteinuria may result from both hepatic overproduction and impaired catabolism (Dixit and Hettiaratchi, 1979; Cohen et al., 1980). In a previous study, we observed that serum lipid abnormalities in children with PNS 
parallel the degree of urinary protein excretion (Hu et al., 2009a). Furthermore, some studies have documented that genetics may exert an important influence on the onset of nephrotic HLP (Gong et al., 2000; Ruf et al., 2003; Hu et al., 2009b).

ApoB has been identified as an important candidate gene for serum lipid abnormalities. Our previous data have demonstrated that genetic variations at restriction enzyme recognition sites of apoB ( $X b a \mathrm{I}$ and EcoRI) might be the risk factors for HLP in both healthy and PNS children (Hu et al., 2009b,c). The apoB 3' VNTR is highly variable, and to date, approximately 26 alleles have been reported (Destro-Bisol et al., 1994). Therefore, this locus is considered an informative marker for association analysis with lipid metabolism. The results of our latest study, published in Clinica Chimica Acta, has suggested that the L allele of the apoB 3' VNTR might be a potential risk factor for HLP in Han children from central China (Hu et al., 2010). However, it remains to be determined whether the effects of apoB 3' VNTR polymorphism on lipid metabolism exist in nephrotic children.

This report is the first to focus on the association of apoB 3' VNTR polymorphism and nephrotic HLP. In the present study, 14 alleles comprising 22-44 HVEs were identified. The presence of high allelic variability at the apoB $3^{\prime}$ VNTR is due to a complex mutational pattern. Earlier studies have reported that a stepwise mutational mechanism that reflects gain or loss of one or a few repeat units probably owing to replication slippage is responsible for the high polymorphism at the apoB 3' VNTR (Deka et al., 1992; Sajantila et al., 1999). The abovementioned alleles (except HVE44) were present in controls, whereas HVE22 and HVE42 were absent in children with PNS. Allele size distribution followed a unimodal curve, with a main peak at HVE35, and the most prevalent genotype was HVE35/35 in both the control and the PNS groups. The genotype and allele distributions in PNS children were not significantly different from those in controls.

Subsequent analysis demonstrated significant variation among the five genotypes for the serum lipid profiles of control children. M/L carriers had TC, LDL-C, and apoB concentrations significantly higher than those of $\mathrm{S} / \mathrm{S}, \mathrm{S} / \mathrm{M}, \mathrm{S} / \mathrm{L}$, or M/M carriers, and individuals with the L allele accordingly exhibited TC, LDL-C, and apoB levels significantly higher than those with $\mathrm{M}$ or $\mathrm{S}$ alleles. These results were consistent with those of other investigators (Hansen et al., 1993; Pan et al., 1998; Rebhi et al., 2008). However, in children with PNS, no significant differences in serum lipid levels were observed for variant genotypes and alleles of the apoB 3' VNTR. The reasons for the variable effects of apoB 3' VNTR polymorphism on serum lipid profiles between control children and children with PNS are unclear. The following explanations are possible.

First, nephrotic HLP is a secondary lipid disorder. In fact, all patients recruited into our study were under preliminary diagnosis, and renal pathological changes had not been identified. Thus, the effect of the apoB 3' VNTR polymorphism on lipid metabolism in a normal population may be hidden by the increased hepatic lipid synthesis triggered by primary glomerular damage (Wiecek et al., 1993). Second, these repeats are present in the 3' untranslated region and do not play any role in the apoB protein sequence. VNTR may be in linkage disequilibrium with other polymorphisms in the same gene or other nearby genes to develop lipid alterations (Pontrelli et al., 2004). Friedl et al. (1990) reported that the apoB 3' VNTR shows strong linkage disequilibrium with a polymorphic EcoRI site in exon 29, which might contribute, in part, to the elevated levels of serum cholesterol and apoB in L carriers. Finally, some environmental factors, such as diet modification and hormone secretion, may be also 
involved in lipid regulation (Hokken-Koelega et al., 1990; Tovar et al., 2002). Further studies are warranted to elucidate the above hypotheses.

\section{ACKNOWLEDGMENTS}

Research supported by the National Natural Science Foundation of China (\#81000306) and the Post-Doctoral Foundation of Anhui Medical University (\#2009KJ02). We sincerely thank the participating children and their families for making this study possible.

\section{REFERENCES}

Bairaktari E, Hatzidimou K, Tzallas C, Vini M, et al. (2000). Estimation of LDL cholesterol based on the Friedewald formula and on apo B levels. Clin. Biochem. 33: 549-555.

Batanian JR, Ledbetter DH and Fenwick RG (1998). A simple VNTR-PCR method for detecting maternal cell contamination in prenatal diagnosis. Genet. Test. 2: 347-350.

Boerwinkle E, Xiong WJ, Fourest E and Chan L (1989). Rapid typing of tandemly repeated hypervariable loci by the polymerase chain reaction: application to the apolipoprotein B 3' hypervariable region. Proc. Natl. Acad. Sci. U. S. A. 86: 212-216.

Choong ML, Koay ES, Khaw MC and Aw TC (1999). Apolipoprotein B 5'-Ins/Del and 3'-VNTR polymorphisms in Chinese, malay and Indian singaporeans. Hum. Hered. 49: 31-40.

Cohen SL, Cramp DG, Lewis AD and Tickner TR (1980). The mechanism of hyperlipidaemia in nephrotic syndrome--role of low albumin and the LCAT reaction. Clin. Chim. Acta 104: 393-400.

Deka R, Chakraborty R, DeCroo S, Rothhammer F, et al. (1992). Characteristics of polymorphism at a VNTR locus 3' to the apolipoprotein B gene in five human populations. Am. J. Hum. Genet. 51: 1325-1333.

Destro-Bisol G, Presciuttini S, d'Aloja E, Dobosz M, et al. (1994). Genetic variation at the ApoB 3'HVR, D2S44, and D7S21 loci in the Ewondo Ethnic Group of Cameroon. Am. J. Hum. Genet. 55: 168-174.

Dixit M, Srivastava A, Choudhuri G and Mittal B (2008). Higher alleles of apolipoprotein B Gene 3' VNTR: risk for gallstone disease. Ind. J. Clin. Biochem. 23: 123-129.

Dixit VM and Hettiaratchi ES (1979). The mechanism of hyperlipidaemia in the nephrotic syndrome. Med. Hypotheses 5: 1327-1331.

Friedl W, Ludwig EH, Paulweber B, Sandhofer F, et al. (1990). Hypervariability in a minisatellite 3' of the apolipoprotein B gene in patients with coronary heart disease compared with normal controls. J. Lipid Res. 31: 659-665.

Gipson DS, Massengill SF, Yao L, Nagaraj S, et al. (2009). Management of childhood onset nephrotic syndrome. Pediatrics 124: 747-757.

Gong WK, Cheung W and Yap HK (2000). Minimal change nephrotic syndrome - a complex genetic disorder. Ann. Acad. Med. Singapore 29: 351-356.

Gordillo R and Spitzer A (2009). The nephrotic syndrome. Pediatr. Rev. 30: 94-104.

Hansen PS, Gerdes LU, Klausen IC, Gregersen N, et al. (1993). Polymorphisms in the apolipoprotein B-100 gene contributes to normal variation in plasma lipids in 464 Danish men born in 1948. Hum. Genet. 91: 45-50.

Hokken-Koelega AC, Hackeng WH, Stijnen T, Wit JM, et al. (1990). Twenty-four-hour plasma growth hormone (GH) profiles, urinary GH excretion, and plasma insulin-like growth factor-I and -II levels in prepubertal children with chronic renal insufficiency and severe growth retardation. J. Clin. Endocrinol. Metab 71: 688-695.

Hu P, Lu L, Hu B and Du PF (2009a). Characteristics of lipid metabolism under different urinary protein excretion in children with primary nephrotic syndrome. Scand. J. Clin. Lab. Invest. 69: 680-686.

Hu P, Qin YH, Jing CX, Lei FY, et al. (2009b). Association of polymorphisms at restriction enzyme recognition sites of apolipoprotein B and E gene with dyslipidemia in children undergoing primary nephrotic syndrome. Mol. Biol. Rep. 36: 1015-1021.

Hu P, Qin YH, Jing CX, Lu L, et al. (2009c). Effect of apolipoprotein B polymorphism on body mass index, serum protein and lipid profiles in children of Guangxi, China. Ann. Hum. Biol. 36: 411-420.

Hu P, Qin YH, Hu B and Lu L (2010). Hypervariability in a minisatellite 3' of the apolipoprotein B gene: allelic distribution and influence on lipid profiles in Han Children from central China. Clin. Chim. Acta 411: 2092-2096.

Hu P, Wang J, Hu B, Lu L, et al. (2012). Dyslipidemia acts as a close link between cardiovascular risk and renal progression in nephrotic children. Asian Biomed. 6: 151-157. 
Huang LS and Breslow JL (1987). A unique AT-rich hypervariable minisatellite 3' to the ApoB gene defines a high information restriction fragment length polymorphism. J. Biol. Chem. 262: 8952-8955.

Khrunin A, Verbenko D, Nikitina K and Limborska S (2007). Regional differences in the genetic variability of FinnoUgric speaking Komi populations. Am. J. Hum. Biol. 19: 741-750.

Lechner BL, Bockenhauer D, Iragorri S, Kennedy TL, et al. (2004). The risk of cardiovascular disease in adults who have had childhood nephrotic syndrome. Pediatr. Nephrol. 19: 744-748.

Mitsnefes MM (2008). Cardiovascular complications of pediatric chronic kidney disease. Pediatr. Nephrol. 23: 27-39.

Noguera NI, Tallano CE, Bragos IM and Milani AC (2000). Modified salting-out method for DNA isolation from newborn cord blood nucleated cells. J. Clin. Lab. Anal. 14: 280-283.

Pan JP, Chiang AN, Chou CY, Chan WL, et al. (1998). Polymorphisms of the apolipoprotein B 3' variable number of tandem repeats region associated with coronary artery disease in Taiwanese. J. Formos. Med. Assoc. 97: 233-238.

Pontrelli L, Sidiropoulos KG and Adeli K (2004). Translational control of apolipoprotein B mRNA: regulation via cis elements in the 5' and 3' untranslated regions. Biochemistry 43: 6734-6744.

Rantala M, Rantala TT, Savolainen MJ, Friedlander Y, et al. (2000). Apolipoprotein B gene polymorphisms and serum lipids: meta-analysis of the role of genetic variation in responsiveness to diet. Am. J. Clin. Nutr. 71: 713-724.

Rebhi L, Omezzine A, Kchok K, Belkahla R, et al. (2008). 5' ins/del and 3' VNTR polymorphisms in the apolipoprotein B gene in relation to lipids and coronary artery disease. Clin. Chem. Lab. Med. 46: 329-334.

Ruf RG, Wolf MT, Hennies HC, Lucke B, et al. (2003). A gene locus for steroid-resistant nephrotic syndrome with deafness maps to chromosome 14q24.2. J. Am. Soc. Nephrol. 14: 1519-1522.

Ruixing Y, Guangqin C, Yong W, Weixiong L, et al. (2007). Effect of the 3'APOB-VNTR polymorphism on the lipid profiles in the Guangxi Hei Yi Zhuang and Han populations. BMC Med. Genet. 8: 45.

Sajantila A, Lukka M and Syvanen AC (1999). Experimentally observed germline mutations at human micro- and minisatellite loci. Eur. J. Hum. Genet. 7: 263-266.

Segrest JP, Jones MK, De Loof H and Dashti N (2001). Structure of apolipoprotein B-100 in low density lipoproteins. J. Lipid Res. 42: 1346-1367.

Soares-Vieira JA, Billerbeck AE, Iwamura ES, Cardoso L, et al. (2000). Post-mortem forensic identity testing: application of PCR to the identification of fire victim. Sao Paulo Med. J. 118: 75-77.

Tovar AR, Murguia F, Cruz C, Hernandez-Pando R, et al. (2002). A soy protein diet alters hepatic lipid metabolism gene expression and reduces serum lipids and renal fibrogenic cytokines in rats with chronic nephrotic syndrome. J. Nutr. 132: 2562-2569.

Verbenko DA, Pogoda TV, Spitsyn VA, Mikulich AI, et al. (2003). Apolipoprotein B 3'-VNTR polymorphism in Eastern European populations. Eur. J. Hum. Genet. 11: 444-451.

Wiecek A, Kokot F, Strzelczyk P, Witkowicz J, et al. (1993). Relationship between renal biopsy histopathology and profile of changes in serum protein, lipids and proteinuria in patients with nephrotic syndrome due to chronic glomerulonephritis. Pol. Arch. Med. Wewn. 90: 426-432.

Yasuda N and Kimura M (1968). A gene-counting method of maximum likelihood for estimating gene frequencies in ABO and ABO-like systems. Ann. Hum. Genet. 31: 409-420. 